\title{
The effects of sport-specific and minimalist footwear on the kinetics and kinematics of three netball-specific movements
}

\author{
J. Sinclair ${ }^{\mathrm{a} *}$, N. Chockalingam ${ }^{\mathrm{b}}$, R. Naemi ${ }^{\mathrm{b}}$ and H. Vincent ${ }^{\mathrm{a}}$ \\ ${ }^{a}$ Division of Sport Exercise and Nutritional Sciences, University of Central Lancashire, Preston, UK; ${ }^{b}$ Faculty of Health Sciences, \\ Staffordshire University, Stoke-on-Trent, UK
}

(Received 2 June 2014; accepted 30 October 2014)

\begin{abstract}
Netball is associated with a high frequency of chronic injuries. There is currently a trend towards the utilisation of minimalist footwear in netball players in lieu of traditional netball trainers. The aim of the current investigation was to examine the influence of netball-specific and minimalist footwear on the kinetics and three-dimensional (3-D) kinematics of three sport specific movements. Twelve female netballers performed three movements, run, cut and vertical jump, whilst wearing a conventional netball trainer and also a minimalist trainer. 3-D kinematics of the lower extremities were measured using an eight-camera motion analysis system alongside kinetic information which was obtained using a force platform. Kinetic/3-D kinematic differences between movements wearing different footwear were examined using paired t-tests. The kinetic analysis revealed that impact parameters were significantly greater in the minimalist footwear in comparison to the netball shoe for all three movements. In addition peak ankle eversion was shown to be significantly greater in the minimalist footwear in the running movement condition. The current study therefore suggests that the utilisation of minimalist footwear for netball training/performance may place netballers at increased risk from chronic injuries based on which a continued utilisation of netball-specific footwear may be recommended.
\end{abstract}

Keywords: netball; footwear; chronic injuries; lower extremity; biomechanics

\section{Introduction}

Netball is an extremely popular team sport that is played by an estimated 20 million people in over 70 countries (Hetherington, King, Visentin, \& Bird, 2009). Netball is characterised by both explosive motions such as cutting and jumping and by more moderate actions such as jogging (Neal \& Sydney-Smith, 1992). Netball has received a paucity of research in sport science settings.

The limited aetiological literature available from netball-based analyses suggests that it is a sport associated with a high injury rate. Hopper (1997) found that 24\% of netball competitors were shown to sustain an injury during the course of a netball tournament. Furthermore, during a three day tournament, Hume and Steele (2000) documented that 238 injuries were observed per 1000 playing hours. More recent evidence obtained from three seasons of league competition has documented injury rates that range from 66.7-71.4 per 1000 participants (Saunders \& Otago, 2009). These aetiological analyses have shown that the majority of injuries occur in the lower extremities and that a high proportion of these are chronic pathologies that relate to over utilisation of the musculoskeletal structures during netball specific motions (McManus, Stevenson, \& Finch, 2006).
Appropriate footwear selection may be able to control the high incidence of injuries in netballers (Shorten 1993). However there is a clear lack of published work investigating the effects of different footwear on the parameters linked to the aetiology of injury development in netballers. Currently there is a trend in netball (like in many sports) to select minimalist footwear for netball performance and training in lieu of netball specific court trainers, although the clinical efficacy of minimalist footwear has yet to be established. Therefore the aim of the current investigation was to examine the influence of netball-specific and minimalist footwear on the kinetics and three-dimensional (3D) kinematics of three sport-specific movements of netballers with information regarding selection of appropriate footwear, which may ultimately help to attenuate the high incidence of lower extremity injuries.

\section{Methods \\ Participants}

Twelve experienced university-level female netballers took part in the current investigation. All were free from musculoskeletal pathology at the time of data collection and provided written informed consent. Age $=20.25 \pm$

*Corresponding author. Email: JKSinclair@uclan.ac.uk 
1.06 years, Height $=1.67 \pm 0.05 \mathrm{~m}$, Mass $=60.51 \pm$ $6.81 \mathrm{~kg}$. The procedure utilised for this investigation was approved by the University of Central Lancashire, ethical committee. No external funding was provided by any of the manufacturers of the footwear examined in this investigation.

\section{Procedure}

Participants completed five repeats of three sport-specific movements - run, cut and vertical jump - in the two footwear conditions. To control for any order effects, the order in which participants performed in each footwear condition was randomised. Kinematic information from the lower extremity joints was obtained using an eight-camera motion capture system (Qualisys Medical AB, Goteburg, Sweden) using a capture frequency of $250 \mathrm{~Hz}$. Dynamic calibration of the system was performed before each data collection session. Calibrations producing residuals $<0.85 \mathrm{~mm}$ and points above 4000 in all cameras were considered acceptable. To measure kinetic information an embedded piezoelectric force platform (Kistler National Instruments, Model 9281CA) operating at $1000 \mathrm{~Hz}$ was utilised. The kinetic and kinematic information were synchronously obtained and interfaced using Qualisys track manager. Participants did not habitually use minimalist footwear and were thus given time to accommodate to them prior to data collection. This involved 5 minutes of running through the testing area in accordance with the guidelines recommended by Sinclair, Greenhalgh, Edmundson, Brooks, and Hobbs (2013).

To quantify lower extremity joint kinematics in all three planes of rotation the current investigation used the calibrated anatomical systems technique (Cappozzo, Catani, Leardini, Benedeti, \& Della, 1995). To define the segment co-ordinate axes of the right foot, shank and thigh, retroreflective markers (19 $\mathrm{mm}$ diameter) were placed unilaterally onto the calcaneus, 1st and 5th metatarsal heads, medial and lateral malleoli, and medial and lateral epicondyles of the femur. To define the pelvis additional markers were positioned onto the anterior (ASIS) and posterior (PSIS) superior iliac spines. The hip joint centre was determined using a regression equation that uses the positions of the ASIS markers (Sinclair, Taylor, Currigan, \& Hobbs, 2013). Carbon fibre tracking clusters were positioned onto the shank and thigh segments. The foot and pelvic segments were tracked using the calcaneus, 1 st and 5th metatarsal markers and the ASIS and PSIS markers respectively. Static calibration trials were obtained allowing the anatomical markers to be referenced in relation to the tracking markers/clusters. Data were collected during run, cut and jump movement as described below:

\section{Run}

Participants ran at an average velocity of $4.0 \mathrm{~m} . \mathrm{s}^{-1} \pm 5 \%$ and struck the force platform with their right (dominant) limb. The average velocity of running was monitored using infra-red timing gates (SmartSpeed Ltd, UK). The stance phase of running was defined as the duration over $>20 \mathrm{~N}$ of vertical force was applied to the force platform.

\section{Cut}

Participants completed $45^{\circ}$ sideways cut movements using an approach velocity of $4.0 \mathrm{~m} . \mathrm{s}^{-1} \pm 5 \%$ striking the force platform with their right (dominant) limb. In accordance with McLean, Huang, Su, and Van Den Bogert (2004) cut angles were measured from the centre of the force plate and the corresponding line of movement was delineated using masking tape so that it was clearly evident to participants. The stance phase of the cut movement was similarly defined as the duration over $>20 \mathrm{~N}$ of vertical force was applied to the force platform.

\section{Jump}

Participants completed counter movement vertical jumps in which they were required to use full arm swing and also to commence and land the jump on the force platform. The landing phase of the jump movement was quantified and was considered to have begun when $>20 \mathrm{~N}$ of vertical force was applied to the force platform and ended at point of body weight stabilisation (Flanagan, Ebben, \& Jensen, 2008).

\section{Data processing}

Dynamic trials were processed using Qualisys Track Manager and then exported as C3D files. Kinematics were quantified using Visual 3-D (C-Motion Inc, Germantown, MD, USA) after marker displacement data were smoothed using a low-pass Butterworth 4th order non-phase shift filter using a cut-off frequency of $15 \mathrm{~Hz}$. Angular kinematics of the lower extremity joints were calculated using an XYZ (sagittal, coronal and transverse) sequence of rotations. All kinematic waveforms were normalised to $100 \%$ of the stance phase then processed trials were averaged. Discrete lower extremity joint kinematic measures extracted for statistical analysis were 1) angle at footstrike, 2 ) peak angle, and 3 ) relative range of motion (representing the angular displacement from footstrike to peak angle).

From the vertical ground reaction force data discrete parameters of average loading rate, instantaneous loading rate, impact peak and time to impact peak were calculated in accordance with previously utilised calculations (Sinclair, Greenhalgh, Edmundson et al., 2013). Vertical ground reaction force parameters were bodyweight (BW) to allow relative comparison of the data amongst participants. 


\section{Footwear}

The footwear used during this study consisted of a netballspecific shoe (Asics lady gel-netburner professional 9) and minimal (Nike Free run 5.0+) footwear, (shoe size 5-7 UK). Each participant performed the run, cut and jump movement in both footwear conditions. The order in which participants ran in the experimental footwear was randomised. The participants were also asked about their preferred footwear choice after all trials were completed.

\section{Statistical analyses}

Descriptive statistics means, standard deviations and 95\% confidence limits (CL) were obtained for each footwear condition. Shapiro-Wilk tests were used to screen the data for normality. Depending on whether the data exhibited a normal distribution, footwear mediated differences in kinetics and kinematic parameters from each movement were examined using either repeated measures or Friedman's analysis of variance (ANOVA). To control type I error, statistical significance was accepted at the $p$ $<0.01$ level. Effect sizes for all significant findings were calculated using $\operatorname{eta}^{2}\left(\eta^{2}\right)$. Finally, a chi-square test was used to examine participants preferred footwear. All statistical actions were conducted using SPSS v21.0 (SPSS Inc, Chicago, USA).

\section{Results}

\section{Subjective footwear preferences}

The subjective preferred footwear questionnaire revealed that 10 participants preferred the netball trainers and two preferred the minimal footwear. The chi-square test was significant $\mathrm{X}^{2}=3.84, \mathrm{p}<0.05$ and showed that significantly more participants preferred the Netball trainers.

\section{Run}

Tables 1 and 2 present the discrete kinetic and 3-D kinematic information obtained during running as a function of footwear.

Kinetics. Time to impact peak was significantly $\left(\mathrm{F}_{(11)}=\right.$ $\left.18.40, \mathrm{p}<0.01, \eta^{2}=0.63\right)$ greater in the netball footwear in comparison to the minimalistic shoes. Average loading rate was also significantly greater $\left(\mathrm{X}^{2}{ }_{(1)}=12.00, \mathrm{p}<\right.$ $\left.0.01, \eta^{2}=0.47\right)$ in the minimalistic footwear compared to the netball trainers. Finally instantaneous loading rate $(\mathrm{F}$ (11) $=19.21, \mathrm{p}<0.01, \eta^{2}=0.68$ ) was shown to be significantly greater in the minimal footwear compared to the netball trainers.

3-D Kinematics. The minimal footwear were associated with a significantly greater $\left(\mathrm{F}_{(11)}=9.60, \mathrm{p}<0.01, \eta^{2}=\right.$ 0.47 ) peak eversion compared to the netball trainers.

Cut

Tables 3 and 4 present the discrete kinetic and 3-D kinematic information from the cut movement as a function of footwear.

Kinetics. Time to impact was significantly longer $\left(\mathrm{F}_{(11)}=\right.$ 9.35, $\mathrm{p}<0.01, \eta^{2}=0.46$ ), in the netball footwear compared to the minimal shoes. Average loading rate was shown to be significantly larger $\left(\mathrm{X}^{2}{ }_{(1)}=10.55, \mathrm{p}<0.01\right.$, $\left.\eta^{2}=0.65\right)$ in the minimalistic footwear compared to the netball trainers. Finally instantaneous loading rate $\left(\mathrm{F}_{(11)}\right.$ $=17.69, \mathrm{p}<0.01, \eta^{2}=0.59$ ) was found to be significantly greater in the minimalistic footwear compared to the netball trainers.

3-D Kinematics. No significant $(\mathrm{p}>0.05)$ differences in 3-D kinematics were observed between footwear.

\section{Vertical Jump}

Tables 5 and 6 present the discrete kinetic and 3-D kinematic information from the vertical jump landing as a function of footwear.

Kinetics. Average loading rate was shown to be significantly larger $\left(\mathrm{t}_{(11)}=5.66, \mathrm{p}<0.05, D=3.41\right)$ in the minimal footwear compared to the netball trainers. Instantaneous loading rate $\left(\mathrm{t}_{(11)}=6.32, \mathrm{p}<0.05, D=3.81\right)$ was found to be significantly greater in the minimal footwear compared to the netball trainers.

3-D Kinematics. No significant $(\mathrm{p}>0.05)$ differences in 3-D kinematics were observed between footwear.

\section{Discussion}

The aim of the current study was to examine the influence of netball-specific and minimal footwear on the kinetics and 3-D kinematics of three sport specific movements. This represents the first analysis to comparatively

Table 1. Kinetic variables during running as a function of footwear.

\begin{tabular}{|c|c|c|c|c|}
\hline & Netball & $\mathrm{CL}$ & Minimalist & $\mathrm{CL}$ \\
\hline Impact peak (BW) & $2.0 \pm 0.6$ & $1.6-2.4$ & $1.9 \pm 0.2$ & $1.8-2.0$ \\
\hline Time to impact peak (ms) & $29.3 \pm 2.1$ & $24.4-34.0$ & $19.1 \pm 1.2 \mathrm{~A}$ & $17.5-22.9$ \\
\hline Average loading rate $\left(\mathrm{BW} \cdot \mathrm{s}^{-1}\right)$ & $68.1 \pm 21.2$ & $54.6-81.5$ & $99.4 \pm 25.8 \mathrm{~A}$ & $83.1-115.8$ \\
\hline Instantaneous Loading rate (BW.s $\left.{ }^{-1}\right)$ & $138.3 \pm 30.5$ & $101.4-174.6$ & $186.4 \pm 29.4 A$ & $152.2-208.6$ \\
\hline
\end{tabular}

Note: $A=$ Significantly different from netball condition 
Table 2. Kinematic variables during running as a function of footwear.

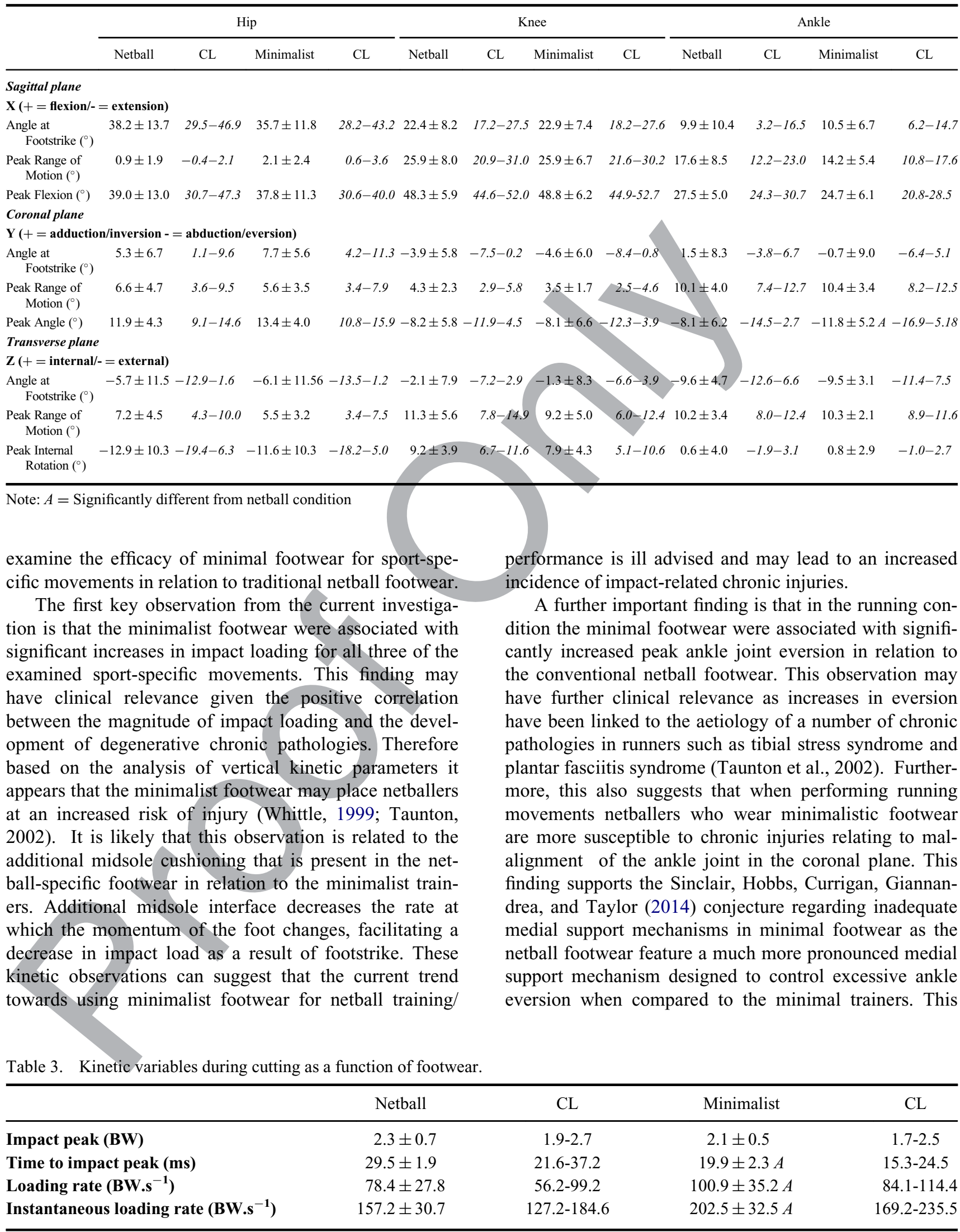

Note: $A=$ Significantly different from netball condition 
Table 4. Kinematic variables during cutting as a function of footwear.

\begin{tabular}{|c|c|c|c|c|c|c|c|c|c|c|c|c|}
\hline & \multicolumn{4}{|c|}{ Hip } & \multicolumn{4}{|c|}{ Knee } & \multicolumn{4}{|c|}{ Ankle } \\
\hline & Netball & $\mathrm{CL}$ & Minimalist & $\mathrm{CL}$ & Netball & $\mathrm{CL}$ & Minimalist & $\mathrm{CL}$ & Netball & $\mathrm{CL}$ & Minimalist & $\mathrm{CL}$ \\
\hline \multicolumn{13}{|l|}{ Sagittal plane } \\
\hline \multicolumn{13}{|c|}{$\mathbf{X}(+=$ flexion$/-=$ extension $)$} \\
\hline $\begin{array}{l}\text { Angle at } \\
\quad \text { Footstrike }\left(^{\circ}\right)\end{array}$ & $38.6 \pm 10.8$ & $31.7-45.4$ & $36.8 \pm 12.6$ & $28.8-44.8$ & $21.3 \pm 6.2$ & $17.4-25.3$ & $23.1 \pm 4.5$ & 20.3-25.9 & $3.7 \pm 13.4$ & $-4.2-12.2$ & $-0.3 \pm 10.8$ & $-7.2-6.6$ \\
\hline $\begin{array}{l}\text { Peak Range of } \\
\text { Motion }\left({ }^{\circ}\right)\end{array}$ & $2.5 \pm 2.8$ & $0.7-4.2$ & $3.1 \pm 3.3$ & $1.0-5.1$ & $32.5 \pm 7.3$ & $27.9-37.1$ & $30.9 \pm 8.6$ & $25.4-36.4$ & $16.6 \pm 13.0$ & $8.3-24.9$ & $18.5 \pm 11.1$ & $11.5-25.6$ \\
\hline Peak Flexion $\left({ }^{\circ}\right)$ & $41.0 \pm 9.8$ & $34.8-47.3$ & $39.9 \pm 12.8$ & $31.7-48.0$ & $53.8 \pm 8.1$ & $48.7-58.9$ & $54.0 \pm 9.6$ & $47.9-60.1$ & $20.3 \pm 6.7$ & $16.1-24.6$ & $18.2 \pm 9.6$ & $12.1-24.3$ \\
\hline \multicolumn{13}{|l|}{ Coronal plane } \\
\hline \multicolumn{13}{|c|}{$\mathbf{Y}(+=$ adduction/inversion $-=$ abduction/eversion $)$} \\
\hline $\begin{array}{l}\text { Angle at } \\
\quad \text { Footstrike }\left({ }^{\circ}\right)\end{array}$ & $-3.4 \pm 6.3$ & $-7.4-0.7$ & $-3.4 \pm 7.0$ & $-7.8-1.0$ & $-4.9 \pm 5.1$ & $-8.1-1.6$ & $-4.6 \pm 5.4$ & & $-0.7 \pm 10.0$ & $-7.1-5.7$ & $-0.6 \pm 9.5$ & $-6.6-5.4$ \\
\hline $\begin{array}{l}\text { Peak Range of } \\
\text { Motion }\left({ }^{\circ}\right)\end{array}$ & $4.7 \pm 3.7$ & $2.3-7.0$ & $4.4 \pm 3.2$ & $2.3-6.4$ & $7.2 \pm 2.9$ & $5.4-9.1$ & & & 2.1 & $1.2-3.8$ & $4.5 \pm 1.6$ & $3.4-5.5$ \\
\hline Peak Angle $\left({ }^{\circ}\right)$ & $1.3 \pm 5.3$ & $-2.1-4.7$ & $0.9 \pm 5.6$ & $-2.6-4.5$ & $-12.1 \pm 5.2$ & $-15.4-8.8$ & & & $-3.2 \pm 9.3$ & $-9.1-2.7$ & $-5.1 \pm 9.0$ & $-10.8-0.6$ \\
\hline \multicolumn{13}{|c|}{ Transverse plane } \\
\hline \multicolumn{13}{|c|}{$\mathbf{Z}(+=$ internal $/-=$ external) } \\
\hline $\begin{array}{l}\text { Angle at } \\
\quad \text { Footstrike }\left({ }^{\circ}\right)\end{array}$ & $-0.5 \pm 9.8$ & $-6.7-5.7$ & $-2.5 \pm 11.0$ & $-9.6-4.4$ & $-0.1 \pm 7.9$ & $-5.1-4.9$ & & & & $-11.7-5.8$ & $-10.1 \pm 3.5$ & $12.3-7.91$ \\
\hline $\begin{array}{l}\text { Peak Range } \\
\text { of Motion }\left(^{\circ}\right)\end{array}$ & $13.5 \pm 6.2$ & $9.6-17.5$ & $10.6 \pm 7.1$ & $6.0-15.1$ & $10.7 \pm 5.6$ & $7.2-14.3$ & & $5.6-12.4$ & $3.9 \pm 2.4$ & 2.4-5.4 & $4.4 \pm 4.4$ & $2.9-5.9$ \\
\hline $\begin{array}{l}\text { Peak Internal } \\
\quad \text { Rotation }\left({ }^{\circ}\right)\end{array}$ & $-14.0 \pm 9.1$ & $-19.8-8.2$ & $-13.1 \pm 9.5$ & $-19.1-7.1$ & $10.6 \pm 4.3$ & & & $6.6-10.9$ & $-4.9 \pm 4.0$ & $-7.4-2.3$ & $-5.7 \pm 3.1$ & $-7.7-3.8$ \\
\hline
\end{tabular}

Table 5. Kinetic variables during vertical jump as a function of footwear.

\begin{tabular}{|c|c|c|c|c|}
\hline & Netball & CL & Minimalist & $\mathrm{CL}$ \\
\hline Impact peak (BW) & $6.85 \pm 0.93$ & $6.1-7.3$ & $6.99 \pm 1.01$ & $5.9-7.6$ \\
\hline Time to impact peak (Ms) & $32.1 \pm 2.6$ & $22.1-36.8$ & $21.4 \pm 3.2$ & $16.2-23.8$ \\
\hline Loading rate $\left(\mathrm{BW} . \mathrm{s}^{-1}\right)$ & $226.66 \pm 26.83$ & $214.1-241.2$ & $329.30 \pm 44.35 \mathrm{~A}$ & 295.4-351.6 \\
\hline Instantaneous loading rate (BW.s $\left.{ }^{-1}\right)$ & $554.21 \pm 43.64$ & $521.7-573.8$ & $618.29 \pm 48.61 A$ & $587.9-650.2$ \\
\hline
\end{tabular}

Note: $A=$ Significantly different from netball condition

Table 6. Kinematic variables during vertical jump as a function of footwear.

\begin{tabular}{|c|c|c|c|c|c|c|c|c|c|c|c|c|}
\hline & & & & & \multicolumn{4}{|c|}{ Knee } & \multicolumn{4}{|c|}{ Ankle } \\
\hline & Netball & $\mathrm{CL}$ & Minimalist & $\mathrm{CL}$ & Netball & $\mathrm{CL}$ & Minimalist & $\mathrm{CL}$ & Netball & $\mathrm{CL}$ & Minimalist & $\mathrm{CL}$ \\
\hline \multicolumn{13}{|l|}{ Sagittal plane } \\
\hline \multicolumn{13}{|c|}{$\mathbf{X}(+=$ flexion $/-=$ extension $)$} \\
\hline $\begin{array}{l}\text { Angle at } \\
\qquad \text { Footstrike }\left({ }^{\circ}\right)\end{array}$ & & $12.0-24.5$ & $19.6 \pm 14.5$ & $10.4-28.8$ & $26.3 \pm 7.3$ & $21.7-30.9$ & $24.6 \pm 6.8$ & $20.3-28.9$ & $-17.9 \pm 9.8$ & $-22.3-9.9$ & $9-19.7 \pm 6.8$ & $-22.6-14.1$ \\
\hline $\begin{array}{l}\text { Peak Range } \\
\quad \text { of Motion }\left({ }^{\circ}\right)\end{array}$ & $30.2 \pm 10.4$ & $23.6-36.7$ & $26.8 \pm 8.6$ & 21.3-32.21 & $52.3 \pm 10.0$ & 45.9-58.7 & $50.2 \pm 9.0$ & 44.4-55.9 & $47.8 \pm 4.9$ & $44.7-50.9$ & $47.2 \pm 7.9$ & $42.1-52.2$ \\
\hline Peak Flexion $\left({ }^{\circ}\right)$ & $48.4 \pm 13.3$ & $39.9-56.9$ & $46.4 \pm 16.1$ & $36.1-56.0$ & $78.6 \pm 15.1$ & $68.9-88.1$ & $74.8 \pm 12.2$ & $67.0-82.6$ & $31.7 \pm 8.7$ & $26.1-37.2$ & $28.8 \pm 8.7$ & 23.3-33.4 \\
\hline \multirow{2}{*}{\multicolumn{13}{|c|}{$\begin{array}{l}\text { Coronal plane } \\
\text { Y }(+=\text { adduction/inversion - = abduction/ eversion })\end{array}$}} \\
\hline & & & & \multicolumn{9}{|c|}{$\mathbf{Y}(+=$ adduction/inversion $-=$ abduction/ eversion $)$} \\
\hline $\begin{array}{l}\text { Angle at } \\
\text { Footstrike }\left({ }^{\circ}\right)\end{array}$ & $-2.0 \pm 5.1$ & $-5.3-1.3$ & $-1.9 \pm 6.1$ & $-5.7-2.0$ & $-3.8 \pm 4.5$ & $-6.7-3.5$ & $-2.6 \pm 5.2$ & $-5.9-0.7$ & $3.0 \pm 7.1$ & $-1.5-7.6$ & $1.9 \pm 6.1$ & $-1.9-5.8$ \\
\hline $\begin{array}{l}\text { Peak Range } \\
\quad \text { of Motion }\left({ }^{\circ}\right)\end{array}$ & $4.2 \pm 3.5$ & $1.9-6.5$ & $3.8 \pm 3.0$ & $1.9-5.7$ & $7.6 \pm 3.4$ & $5.4-9.8$ & $9.1 \pm 4.5$ & $-11.9-6.2$ & $11.7 \pm 3.8$ & $9.3-14.1$ & $1 \quad 12.0 \pm 4.4$ & $-14.8-9.2$ \\
\hline Peak Angle $\left(^{\circ}\right)$ & $2.2 \pm 5.8$ & $-1.5-5.9$ & $1.9 \pm 6.0$ & $-1.9-5.7$ & $-11.5 \pm 6.4$ & $-15.5-7.4$ & $-11.7 \pm 6.2$ & $-15.6-7.7$ & $-8.6 \pm 10.0$ & $-14.9-2.3$ & $3-10.1 \pm 9.5$ & $-16.1-4.1$ \\
\hline \multicolumn{13}{|l|}{ Transverse plane } \\
\hline \multicolumn{13}{|c|}{$\mathbf{Z}(+=$ internal $/-=$ external $)$} \\
\hline $\begin{array}{l}\text { Angle at } \\
\text { Footstrike }\left({ }^{\circ}\right)\end{array}$ & $-11.9 \pm 9.1$ & $-17.7-6.1$ & $-9.2 \pm 8.1$ & $-14.4-4.4$ & $0.4 \pm 4.1$ & $-2.2-3.1$ & $-2.0 \pm 6.2$ & $-5.9-1.9$ & $-5.6 \pm 4.6$ & $-8.5-2.7$ & $-6.1 \pm 3.1$ & $-8.0-4.1$ \\
\hline $\begin{array}{l}\text { Peak Range } \\
\text { of Motion }\left({ }^{\circ}\right)\end{array}$ & $4.2 \pm 2.8$ & $2.5-5.9$ & $4.9 \pm 4.2$ & $2.2-7.6$ & $-4.0 \pm 3.4$ & $-6.5-2.1$ & $3.4 \pm 3.2$ & $1.4-5.4$ & $4.6 \pm 3.2$ & $2.5-6.0$ & $5.3 \pm 3.4$ & $-7.5-3.1$ \\
\hline $\begin{array}{l}\text { Peak Internal } \\
\quad \text { Rotation }\left({ }^{\circ}\right)\end{array}$ & $-16.2 \pm 8.0$ & $-21.2-11.1$ & $-14.2 \pm 7.2$ & $-18.7-9.6$ & $-3.9 \pm 3.4$ & $-5.9-1.7$ & $-5.4 \pm 5.0$ & $-8.5-2.2$ & $-1.0 \pm 4.6$ & $-3.9-1.9$ & $-0.8 \pm 4.4$ & $-3.6-2.0$ \\
\hline
\end{tabular}


observation mirrors the kinetics findings in that the trend towards the utilisation of minimalist footwear for netball is inadvisable and may facilitate an increase in chronic injury aetiology related to excessive ankle eversion.

The subjective selections support the results from the kinetic/3-D kinematic analysis in that a significant majority of participants selected the netball-specific footwear as their footwear preference. This opposes the observations of Geil (2002) and Shorter, Lake, Smith, and Lauder (2011) who noted significant subjective preferences for minimalist footwear in other sports. This observation may relate to the high impact nature of netball, which is evidenced by the kinetic values noted in the current investigation. Due to this, netball players may have selected the footwear with the greatest degree of midsole interface which may have provided more protection and comfort. A potential limitation with regard to this observation is that all of the participants habitually wore netball specific footwear and thus there may have been a bias not only in the subjective preferences but also in the kinetic/3-D kinematic observations from the current investigation. It may be advisable for the current investigation to be repeated using a participants sample of netballers who habitually train/perform using minimal footwear.

That the current investigation quantified foot kinematics during the movement tasks using retroreflective markers positioned onto the experimental footwear may serve as a potential limitation of this work. Previous work has investigated the differences in foot kinematics when using retroreflective markers positioned onto the shoe and those placed onto the foot itself through holes cut into the shoe. It has been demonstrated that markers placed onto the shoe can produce errors, particularly when quantifying angles in the coronal and transverse planes (Sinclair, Greenhalgh, Taylor et al., 2013). However, cutting holes in the footwear was shown to reduce the structural integrity of the shoe itself and may influence the athlete's perception of the experimental footwear (Sinclair, Greenhalgh, Taylor et al., 2013). Considering that footwear effect of movement biomechanics was the main objective of this study, maintaining the integrity of footwear was given priority in the current study.

In conclusion, the current investigation adds to the current knowledge in the area of footwear biomechanics by providing a comprehensive evaluation of the kinetics and 3-D kinematics of movement in minimal and netballspecific footwear during three sport specific movements. The significant increases in both impact loading for all movements and ankle eversion during running in minimalist footwear suggests this type of shoe may place netballers at an increased risk from development of chronic injuries. The current study concluded that the adoption of minimalist footwear for netball training/performance may not be evidence based and continued utilisation of netball-specific footwear is recommended.

\section{References}

Cappozzo, A., Catani, F., Leardini, A., Benedeti, M. G., \& Della C. U. (1995). Position and orientation in space of bones during movement: Anatomical frame definition and determination. Clinical Biomechanics, 10, 171-178.

Flanagan, E. P., Ebben, W., \& Jensen, R. L. (2008). Reliability of the reactive strength index and time to stabilization during depth jumps. Journal of Strength and Conditioning Research, 22, 1677-1682.

Geil, M. D. (2002). The role of footwear on kinematics and plantar foot pressure in fencing. Journal of Applied Biomechanics, $18,155-162$.

Hetherington, S., King, S., Visentin, D., \& Bird, M. L. (2009). A kinematic and kinetic case study of a netball shoulder pass. International Journal of Exercise Science, 2, 243-253.

Hopper, D. M. (1997). Somatotype in high performance female netball players may influence player position and the incidence of lower limb and back injuries. British Journal of Sports Medicine, 31, 197-199.

Hume, P. A, \& Steele, J. R. (2000). A preliminary investigation of injury prevention strategies in netball: Are players heeding the advice? Journal of Science and Medicine in Sport, 3, 406-413.

McLean, S. G., Huang, X., Su. A., \& Van Den Bogert, A. J. (2004). Sagittal plane biomechanics cannot injure the ACL during sidestep cutting. Clinical biomechanics, 19, $828-838$.

McManus, A., Stevenson, M. R., \& Finch, C. F. (2006). Incidence and risk factors for injury in non-elite netball. Journal of Science and Medicine in Sport, 9, 119-124.

Neal, R. J., \& Sydney-Smith, M. (1992). The effects of footfall pattern and passing height on ground reaction forces in netball. Australian Journal of Science and Medicine in Sport, $24,73-78$

Saunders, N., \& Otago, L. (2009). Elite netball injury surveillance: Implications for injury prevention. Journal of Science and Medicine in Sport, 12, S63.

Shorten, M. R. (1993). The energetics of running and running shoes. Journal of Biomechanics, 26, 41-51.

Shorter, K., Lake, J., Smith, N., \& Lauder, M. (2011). Influence of the foot-floor interface on squatting performance. Portuguese Journal of Sport Sciences, 11, 385-388.

Sinclair, J., Greenhalgh, A., Edmundson, C. J., Brooks, D., \& Hobbs, S. J. (2013). The efficacy of barefoot and shod running and shoes designed to mimic barefoot running. Footwear Science, 5, 45-53.

Sinclair, J., Greenhalgh, A., Taylor, P. J., Edmundson, C. J., Brooks, D., \& Hobbs, S. J. (2013). Differences in tibiocalcaneal kinematics measured with skin-and shoe-mounted markers. Human Movement, 14, 64-69.

Sinclair, J., Hobbs, S. J., Currigan, G., Giannandrea, M., \& Taylor, P. J. (2014). Tibiocalcaneal kinematics during barefoot and in barefoot-inspired shoes in comparison to conventional running footwear. Movement and Sport Sciences, 1, $67-75$.

Sinclair, J., Taylor, P. J., Currigan, G., \& Hobbs, S. J. (2013). The test-retest reliability of three different hip joint centre location techniques. Movement and Sport Sciences, 83, $31-39$

Taunton, J. E., Clement, D. B., \& McNicol, K. (1982). Plantar fasciitis in runners. Canadian Journal of Applied Sport Sciences, $7,41-44$.

Whittle, M. W. (1999). The generation and attenuation of transient forces beneath the foot; a review. Gait and Posture, 10, 264-275. 